\title{
Ribosomal DNA sequences of Glugea anomala, G. stephani, G. americanus and Spraguea lophii (Microsporidia): phylogenetic reconstruction
}

\author{
Cecile Pomport-Castillon ${ }^{1, *}, J^{\prime}$ ohan F. De Jonckheere ${ }^{2}$, B. Romestand ${ }^{1}$
}

${ }^{1}$ Laboratoire de Parasitologie et Immunologie, Université Montpellier II, C.C. 096, Place Eugène Bataillon, 34095 Montpellier Cédex, France

${ }^{2}$ Protozoology Laboratory, Biosafety and Biotechnology, Institute of Hygiene and Epidemiology, 1050 Brussels, Belgium

\begin{abstract}
The microsporidian species Glugea anomala, $G$ stephani, $G$. americanus and Spraguea lophii were compared by using sequence data derived from their small subunit rDNA genes which were amplified by polymerase chain reaction and directly sequenced. These sequence data and published data of $G$. atherinae were analyzed and were used to infer a phylogenetic tree. The 5 microsporidian fish parasites appeared to be closely related. The higher sequence similarities demonstrated among $G$. anomala, $G$. stephani and $G$. atherinae suggest that these 3 parasites are in fact only 1 species of Glugea. Moreover, the higher sequence similarities between S. lophii and G. americanus support the transfer of the latter Glugea species into the genus Spraguea.
\end{abstract}

KEY WORDS: Sequence $\cdot$ SSUrDNA $\cdot$ Microsporidia $\cdot$ Glugea S Spraguea $\cdot$ Taxonomy

\section{INTRODUCTION}

Microsporidia are obligately intracellular parasites and are found in many vertebrates and invertebrates (Sprague \& Vavra 1977). However, most Microsporidia are found in insects and fishes. Many species belong. ing to the genus Glugea were described in several species of teleost fishes (Canning \& Lom 1986). They have been identified and described mainly on the basis of their tissue preference, morphology and developmental life cycle as demonstrated by electron microscopy (Canning \& Lom 1986). Molecular analyses based on rDNA sequence data are increasingly applied to the phylum Microsporidia. The small subunit (SSU) rRNA or rDNA sequences have already been determined for many Microsporidia including Vairimorpha necatrix (Vossbrinck et al. 1987), Ameson michaelis (Zhu et al. 1993a), Encephalitozoon cuniculi (Zhu et al. 1993b), Septata intestinalis (Zhu et al. 1993c), Enterocytozoon bieneusi (Zhu et al. 1994) and Glugea atherinae (Genbank: U15987).

\footnotetext{
•E-mail: pomport@crit.univ-montp2.fr
}

Recently, a phylogenetic analysis based on riboprinting of the SSU and LSU rDNA of 7 microsporidian species has shown that Glugea anomala, G. stephani and $G$. atherinae are very closely related while $G$. americanus may be more closely related to Spraguea lophii than to the other Glugea spp. (Pomport-Castillon et al. 1997a). When we consider the species description, their taxonomic status is questionable for several reasons. (1) Experimental infection of stickleback with $G$. hertwigi obtained from the smelt Osmerus eperlanus, carried out successfully by Weissenberg (1968), led Canning \& Lom (1986) to question the validity of the species G. anomala and G. hertwigi. (2) Successful experimental transmission of G. atheninae, a parasite of the sand smelt Atherina boyeri, to the flounder Platichthys flesus (Mathieu-Daudé et al. 1992) and to the turbot Scophthalmus maximus (Leiro et al. 1993) calls the validity of this species and of $G$. stephani into question. (3) In spite of a very similar parasitism of angler fish (little white cysts in grapes in the nervous system), genus Lophius, 2 species have been described: Spraguea lophii for the European angler fish ( $L$. budegassa and $L$. piscatorius) and $G$. americanus 
for the American angler fish (L. americanus) (Loubés et al. 1979, Takvorian \& Cali 1986).

In order to improve the taxonomy of microsporidian parasites of fish, in particular of the genera Glugea and Spraguea, we have sequenced the SSU rDNA of $G$. anomala, G. stephani, $G$. americanus and S. lophii. We report here the SSU rDNA sequences of these 4 Microsporidia and a phylogenetic reconstruction based on them.

\section{MATERIALS AND METHODS}

Fishes and Microsporidia. The sand smelt Atherina boyeri Risso, 1810, host of Glugea atherinae (Berrebi, 1979), the stickleback Gasterosteus aruleatus L., 1758, host of Glugea anomala (Moniez, 1887), the flounder Platichthys flesus L., 1758, host of Glugea stephani (Hagenmulter, 1899), the American angler fish Lophius americanus Valenciennes, 1837, host of Glugea americanus (Takvorian and Cali, 1986 ) and the European angler fish Lophius piscatorius L., 1758 and L. budegassa Spinosa, 1807, hosts of Spraguea lophii (Doflein, 1898) were collected directly from fishermen or from a dealer. Fishes were dissected and xenomas were isolated from parasitized host organs. The spores were recovered from the cysts in a phosphate-buffered saline (PBS) solution ( $\mathrm{pH} \mathrm{7.2)}$ and purified on a Percoll gradient $(25,50,75$ and 100\%) (Jouvenaz 1981, Pomport-Castillon et al. 1997b). The spore suspensions obtained were stored at $-20^{\circ} \mathrm{C}$ in PBS.

Microsporidian DNA isolation. After centrifugation $(3000 \times g)$, the spore pellet was resuspended in a solution containing $0.4 \mathrm{ml}$ buffer $10.5 \mathrm{M} \mathrm{NaCl}, 0.2 \mathrm{M}$ Tris $\mathrm{HCl} \mathrm{pH} \mathrm{7.5,0.01} \mathrm{M} \mathrm{ethylenediamine} \mathrm{tetraacetic} \mathrm{acid}$ and $1 \%$ sodium n-lauroyl sarcosine) and $0.4 \mathrm{~g}$ glass beads. The DNA was liberated from the spores by shaking in a Mini Bead Beatter (Biospec. Product, Bartlesville, OK, USA). The aqueous phase was extracted with Tris-saturated phenol and precipitated with ethanol (Pomport-Castillon at al. 1997a).

PCR amplification and sequencing. The SSU rDNA was amplified using the forward primer 5'-GGTTG-

Table 1. Base compocition of the SSU rDAIA scquonccs of 5 species uf iviluosporidia. S: Spraguea; G: Glugea

\begin{tabular}{|c|c|c|c|c|c|}
\hline & S. lophii & G. americanus & G. anomala & G. stephani & G. atherinae \\
\hline No of bases & 1175 & 1174 & 1165 & 1165 & 1165 \\
\hline$A(\%)$ & 30.6 & 30.5 & 29.4 & 29.4 & 29.5 \\
\hline $\mathrm{G}(\%)$ & 31.6 & 31.8 & 32.4 & 32.4 & 32.3 \\
\hline $\mathrm{T}(\%)$ & 20.1 & 20.1 & 19.0 & 19.0 & 19.0 \\
\hline $\mathrm{C}(\%)$ & 17.7 & 17.6 & 19.2 & 19.2 & 19.2 \\
\hline$C+G\left(D^{\prime}(i)\right)$ & 4.9 .3 & 49.4 & 51.6 & 51.6 & 51.5 \\
\hline
\end{tabular}

ATTCTGCCTGACGT-3' (Baker et al. 1994) and one of the reverse primers 5'-GACGGGCGGTGTGTACAAAG-3' or 5'-GGTCCGTGTTTCAAGACGG-3' (Vossbrinck et al. 1993). Amplification conditions were $1 \mathrm{~min}$ at $94^{\circ} \mathrm{C}, 1.5 \mathrm{~min}$ at $55^{\circ} \mathrm{C}$ and $2 \mathrm{~min}$ at $72^{\circ} \mathrm{C}$ for 30 cycles using Taq DNA polymerase (Boehringer Mannheim, Germany) (Pomport-Castillon et al. 1997a). The initial primer and additional primers were used to sequence the SSU rDNA. Direct sequencing of a purified fragment was accomplished using the 70170 Sequenase $^{T M}$ PCR Product Sequencing kit (Amersham, United States Biochemicals, Cleveland, Ohio, USA). PCR and sequencing were done 4 times with different isolates to take any variability into account.

GenBank/NCBI accession numbers are: Spraguea lophii AF056013, Glugea americanus AF056014, $G$. stephani AF056015 and $G$. anomala AF056016. The $G$. atherinae sequence was obtained from GenBank (accession no. U15987).

Phylogenetic analysis. Base compositions of the sequenced fragments were analysed by a DNA statistics program (ESGS, France). The alignments were done using the computer program Multalign (INRA, France). Using the Clustal algorithm percent similarities and divergents were calculated and allowed to find the shortest tree built with the Neighbour Joining method (Saitou \& Nei 1987, Higgins \& Sharp 1988). Moreover, a phylogenetic tree was constructed using DOLLOP program (parsimony) of the PHYLIP package (Felsenstein 1989).

\section{RESULTS}

The base composition and GC contents of the SSU rDNA sequences of Glugea anomala, $G$. stephani, $G$. atherinae, $G$. americanus and Spraguea lophii sequences are reported the Table 1 . The base composition appears to be nearly identical for $G$. anomala, $G$. stephani and $G$. atherinae with a small bias to $G+C$ bases, whereas the 2 other species have a bias to $A+T$ bases. The SSU rDNA shows little variation among the taxa analyzed. The $G$. anomala and $G$. stephani sequences are identical and only 1 base was different between these ? and the $G$. atherinae sequence. By contrast, about 160 bases were different between these 3 sequences and the $G$. americanus and $S$. lophii sequences. The $G$. americanus and $S$. lophii sequences were very similar with only 7 base differences between the 2 sequences (Table 2).

Table 2 shows the percent divergence among the 5 species. The dis- 
Table 2. Percent sequence divergence among 5 species of Microsporidia. S: Spraguea; G: Glugea

\begin{tabular}{|lcccc|}
\hline & S. Lophii & G. americanus & G. anomala & G. stephani \\
\hline S. lophii & 0.0 & & & \\
G. americanus & 0.6 & & & \\
G. anomala & 16.0 & 15.8 & & \\
G. stephani & 16.0 & 15.8 & 0.0 & 0.1 \\
G. atherinae & 15.9 & 15.7 & 0.1 & 0.1 \\
\hline
\end{tabular}

tances between Glugea atherinae and G. anomala/G. stephani and between $G$. americanus and Spraguea lophii are smaller $(0.1$ and $0.6 \%$, respectively) than that between $G$. atherinae and $G$. americanus/S. lophii (15.7/15.9\%).

Fig. 1 illustrates a phylogenetic tree of the 5 species showing 2 clusters, i.e. the first grouping: Glugea anomala, G. stephani and G. atherinae, and the second grouping: G. americanus and Spraguea lophii. Such a tree suppports the exclusion of $G$. americanus from the genus Glugea. Moreover, the analysis of the SSU IDNA sequences using the DOLLOP programs of the PHYLIP package generated a tree showing the phylogenetic relationship between the different fish Microsporidia (Fig. 2).

\section{DISCUSSION}

Using conserved primers in the SSU rDNA, we obtained sequences of 4 microsporidian species belonging to the genera Glugea and Spraguea ( $G$. anomala, $G$. stephani, $G$. americanus and $S$. lophii) and have compared these with a sequence of another species of the Glugea genus, $G$. atherinae.

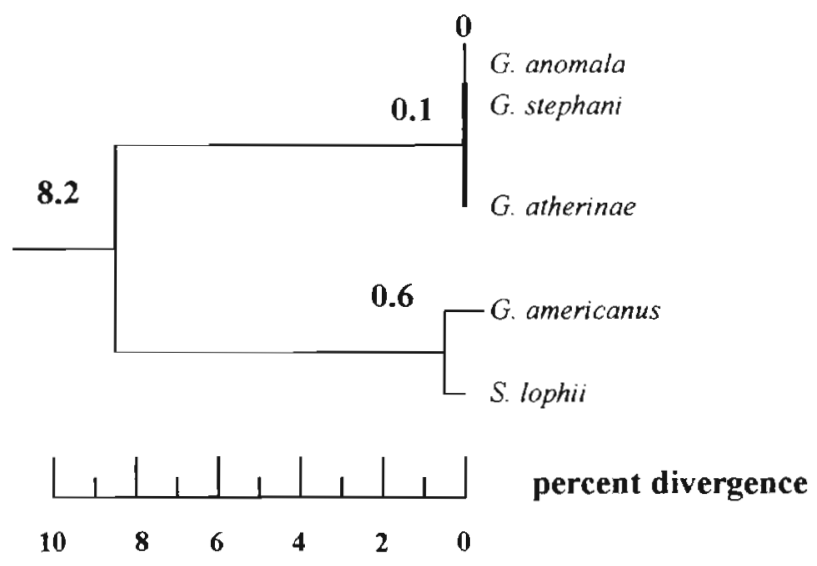

Fig. 1. Phylogenetic tree of the 5 species of Microsporidia based on the percent divergence. G: Glugea; S: Spraguea
Our study and some recent riboprinting experiments on several microsporidian species (Pomport-Castillon et al. 1997a) show the following.

The SSU rDNA sequences of the 5 species are closely related since the lowest similarity is about $80.3 \%$ as observed between Glugea anomala, $G$. stephani and $G$. americanus. Microsporidian fish parasites constitute a homogeneous group in comparison with other species. Malone \& Mclvor (1995) have shown a great sequence variability between species of the Nosema genus parasitising different classes of arthropods: $62.4 \%$ similarity was observed between $N$. bombycis and $N$. apis.

The analysis of the base composition outlines a linking of some of these species. Pieniazek et al. (1995) have shown a variation of the GC content of 15 microsporidian species with, at the extreme, $34 \%$ for Nosema bombycis and $56 \%$ for Vavraia oncoperae. However, in the same genus the GC content is very similar, e.g. 34 to $38 \%$ for Nosema spp. Malone \& Mclvor (1995) have demonstrated that, mainly in Protozoa, the ratio $\mathrm{G}+\mathrm{C} / \mathrm{A}+\mathrm{T}$ is less than or equal to 1 . This is consistent for Glugea americanus and Spraguea lophii, but not for the 3 other species which show a majority of $\mathrm{C}+\mathrm{C}$ bases.

Glugea anomala, G. stephani and $G$. atherinae are very closely related while $G$. americanus appears to be more closely related to Spraguea lophii than to the other 3 Glugea species. Indeed, the $G$. anomala and $G$. stephani sequences are identical or almost identical ( $99.9 \%$ similarity) to the $G$. atherinae sequence. This result is in accordance, for these 3 species, with a well established homogenous life cycle inducing voluminous xenomas encapsulated in connective tissues of their host fishes. In spite of some morphological differ-

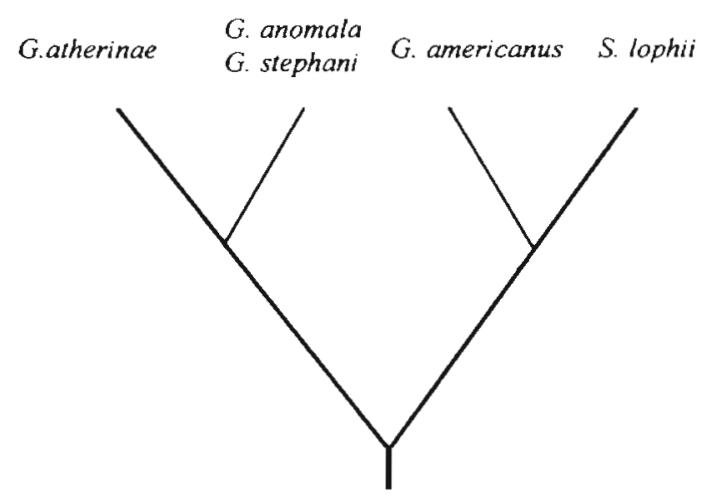

Fig. 2. Phylogenetic tree of the 5 species of Microsporidia based on SSU rDNA sequence using the Dollop program Bootstrap values are $100 \%$ or close to this for all branching node. G: Glugea; $S$ : Spraguea 
ences in the spores, experimental infections have been carried out successfully between some of these species (Mathieu-Daudé et al. 1992, Leiro et al. 1993). These observations and our results suggest that $G$. anomala, $G$. stephani and $G$. atherinae could be only 1 species. However, there is evidence that some Microsporidia are cross-infective between hosts and that the morphology can be altered in different hosts (Canning \& Lom 1986). Moreover, Docker et al. (1997) have demonstrated the existence of genetic variability in the rDNA sequences of another microsporidian parasites in the same host species. Indeed, the authors have sequenced 2 samples of Loma salmonae and have shown differences of 2 nucleotides. Such intra-species variability can explain the difference observed between $G$. anomala, $G$. stephani and $G$. atherinae by riboprinting and sequencing, and could be an argument in favour of the existence of only one species.

Glugea americanus and Spraguea lophii, in spite of causing a very similar parasitism of the American and the European angler fishes' nervous systems respectively, produce different spores. G. americanus has oval and uninucleated spores of $2.8 \times 1.5 \mu \mathrm{m}$ while $S$. lophii has 2 types of spores: oval, uninucleated ones and curved, binucleated ones with a size of $4.2 \times 2.5 \mu \mathrm{m}$ and $3.7 \times 1.4 \mu \mathrm{m}$, respectively (Loubés et al. 1979, Lom \& Dykova 1992). However, it is important to mention that the early proliferative forms and the complete development of $G$. americanus are unknown and only spores and xenomas have been described (Takvorian \& Cali 1986). In our study, these 2 angler fish parasite species have a higher SSU rDNA sequence similarity $(98.6 \%)$ which is due to only 2 transitions, 2 transversions and 1 deletion. The closely related sequences determined here confirm the result obtained by riboprinting and could support the transfer of $G$. americanus into the genus Spraguea. Indeed, percent similarities and divergence have already been used to rename species. Zhu et al. (1993c) and Hartskel et al. (1995) have justified the transfer of Septata intestinalis to the genus Encephalitozoon by a lower divergence $(21.9 \%)$ and a high similarity $(70 \%)$ between $S$. intestinalis and Encephalitozoon cuniculi. However, it would be of interest to know how many nucleotide substitutions constitute differences between species and genera. Molecular systematics are clearly helpful when there are many nucleotide differences but slight differences create difficulties in interpretation.

The low numbers of differences between gene sequences of these species give little information. The present work is the second step, after riboprinting, in the study of the phylogeny relationships of these 5 microsporidian species and more sequence data have to be obtained. Moreover, further steps should be taken to confirm the hypotheses inferred from the mol- ecular data: (1) an examination of the morphology of Glugea americanus and description of the life cycle to see whether it exhibits sporal dimorphism as is present in Spraguea lophii; (2) the separation of the 2 spore types of $S$. lophii and analysis of both sequences to confirm that they belong to the same species; (3) crosstransmission experiments if possible among the $G$. anomala, G. atherinae, G. stephani group; and (4) sequencing of the ITS and the LSU rDNA or another gene more variable among the 5 species under study.

\section{LITERATURE CITED}

Baker MD, Vossbrinck CR, Didier ES, Maddox JV, Undeen AH (1994) Phylogenetic relationships among Vairimorpha and Nosema species (Microspora) based on ribosomal RNA sequence data. J Invertebr Pathol 64:100-106

Canning EU, Lom J (1986) The Microsporidia of vertebrates. Academic Press, New York

Docker MF, Devlin RH, Richard J, Khattra J, Kent ML (1997) Sensitive and specific polymerase chain reaction assay for the detection of Loma salmonae (Microsporea). Dis Aquat Org 29:41-48

Felsenstein J (1989) PHYLIP-phylogeny inference package (version 3.2). Cladistics 5:164-166

Hartskeel RA, Van Gool T, Schuitema ARJ, Didier ES, Terpstra WJ (1995) Genetic and immunological characterization of the microsporidian Septata intestinalis Cali. Kotler and Orenstein. 1993: reclassification to Encephalitozoon intestinalis. Parasitology 110:277-285

Higgins DG, Sharp PM (1988) CLUSTAL: a package for performing multiple sequence alignment on a microcomputer. Gene 73:237-244

Jouvenaz DP (1981) Percoll: an effective medium for cleaning microsporidian spores. J Invertebr Pathol 37:219

Leiro J, Bos J, Iglesias R, Estevez J, Fernandez J, Sanmartin ML (1993) Experimental infection of turbot (Scophthalmus maximus L.) with a microsporean parasite (Glugea atherinae Berrebi, 1979) of the sand smelt (Atherina boyeri). Aquaculture 55:235-242

Lom J, Dykova I (1992) Protozoan parasites of fishes. Dev Aquac Fish Sci 26:125-157

Loubés C, Maurand J, Ormières R (1979) Étude ultrastructurale de Spraguea lophii (Doflein, 1898), microsporidie parasite de la baudroie: essai d'interprétation du dimorphisme sporal. Protistologia 15:43-54

Malone LA, Mclvor CA (1995) DNA probes for two Microsporidia. Nosema bornbycis and Nosema costelytrae. J Invertebr Pathol 65:269-273

Mathieu-Daudé F, Faye N, Coste F, Manier F, Marques A. Bouix G (1992) Occurrence of microsporidiosis in marine rultured gilt-head sea brcam from the Lañy̆uedur cuasi: a problem of specificity in the genus Glugea (Protozoa, Microspora). Bull Eur Assoc Fish Pathol 12:67

Pieniazek NJ, Da Silva AJ, Slemenda SB, Vivesvara GS, Kurtti TJ, Fries I Yasunaga C, Ditrich O, Lom J (1995) Molecular taxonomy of microsporidia based on complete small subunit ribosomal RNA sequences and secondary structures. Soc Invertebr Pathol 28th Annual meeting, University Ithaca, New York

Pomport-Castillon C, Romestand B, De Jonckheere JF, (1997a) Identification and phylogenetic relationships of Microsporidia by riboprinting. J Eukaryot Microbiol 44: $540-544$ 
Pomport-Castillon C, Gasc C, Romestand B (1997b) Development and characterization of monoclonal antibodies against spores of Glugea atherinae (Protozoa-Microsporidia-Fish parasites) and future prospects. J Eukaryot Microbiol 44:643-648

Saitou N, Nei M (1987) The neighbour-joining method: a new method for reconstructing phylogenetic trees. Mol Biol Evol 4:406-425

Sprague V, Vavra J (1977) Classification and phylogeny of the Microsporidia. In: Bulla LA, Cheng TC (ed) Comparative pathology II. Plenum Press, New York

Takvorian PM, Cali A (1986) The ultrastructure of spores (Protozoa: Microsporoda) from Lophius americanus, the angler fish. J Protozool 33:570-575

Vossbrinck CR, Maddox JV, Friedman S, Debrunner-Vossbrinck BA, Woese CR (1987) Ribosomal RNA sequence suggests microsporidia are extremely ancient eukaryotes. Nature 326:411-414

Vossbrinck CR, Baker MD, Didier ES, Debrunner-Vossbrinck BA, Shadduck JA (1993) Ribosomal DNA sequences of Encephalitozoon hellem and Encephalitozoon cuniculi:

Editorial responsibility: Wolfgang Körting,

Hannover, Germany species identification and phylogenetic construction. J Eukaryot Microbiol 40:354-362

Weissenberg $\mathrm{R}$ (1968) Intracellular development of the Microsporidian Glugea anomala Moniez in hypertrophying migratory cells of the fish Gasterosteus aculeatus, an example of the formation of the xenoma tumors. J Protozool 15:44-57

Zhu X, Wittner M, Tanowitz HB, Cali A, Weiss LM (1993a) Nucleotide sequence of the small subunit rRNA of Ameson michaelis. Nucleic Acids Res 21:3895

Zhu X, Wittner M, Tanowitz HB, Cali A, Weiss LM (1993b) Nucleotide sequence of the small subunit rRNA of Encephalitozoon cuniculi. Nucleic Acids Res 21:1315

Zhu X, Wittner M, Tanowitz HB, Cali A, Weiss LM (1993c) Nucleotide sequence of the small subunit rRNA of Septata intestinalis. Nucleic Acids Res 21:4846

Zhu X, Wittner M, Tanovitz HB, Cali A, Weiss LM (1994) Ribosomal RNA sequences of Enterocytozoon bieneusi, Septata intestinalis, Ameson michaelis: phylogenetic construction and structural correspondence. J Eukaryot Microbiol 41:204-209

Submitted: April 10, 1999; Accepted: December 9, 1999

Proofs received from author(s): February 14, 2000 